\title{
Flinders University rural medical school student program outcomes
}

Leesa Walker, Vivian Isaac, Lucie Walters, Jonathan Craig

\section{Background and objective \\ The impact of Australian Government Rural Clinical School (RCS) programs on the geographical maldistribution of the Australian medical workforce is important to report.}

\section{Methods}

This data linkage study compared graduates of the Flinders University medical program who have undergone training in a metropolitan tertiary hospital (Flinders Medical Centre, Adelaide) with those who participated in the Parallel Rural Community Curriculum (PRCC) RCS Program based in rural towns of South Australia between 1999 and 2012. Australian Health Practitioners Authority data were used to determine their location of practice in 2017.

\section{Results}

In 2017, more than one-third (36.8\%) of PRCC graduates were working in nonmetropolitan Modified Monash (MM) 2-7, compared with $20.7 \%$ of city campus graduates (odds ratio $2.2 ; 95 \%$ confidence interval: 1.6, 3.0; $P<0.001$ ). The difference was even more evident when comparing smaller rural centres in MM 3-7 and MM 5-7.

\section{Discussion}

The study demonstrates the strong correlation between the Flinders University RCS Program in South Australia and long-term rural medical workforce outcomes.
AUSTRALIAN GOVERNMENT RURAL CLINICAL SCHOOL (RCS) programs were developed as rural workforce initiatives to provide experiences that positively influence medical graduates to choose rural careers. ${ }^{1}$ The programs mandate that $25 \%$ of all domestic medical students spend a year or more of their training based in a rural location. The impact of this substantial investment on the geographical maldistribution of the Australian medical workforce is important to report. Flinders University was a pioneer in rural community-engaged medical education, with the introduction of a Parallel Rural Community Curriculum (PRCC) in 1997, wherein students are based in rural general practice and follow their patients and general practice supervisors into local hospitals. ${ }^{2}$ The aim of this data linkage study was to compare the graduates of the Flinders University medical program who have undergone training in a metropolitan tertiary hospital (Flinders Medical Centre, Adelaide) with those who participated in the PRCC Program based in rural towns of South Australia and Victoria between 1999 and 2012.

\section{Methods}

Australian Health Practitioners Authority (AHPRA) data were used to compare their registration type, speciality and current location of practice in April, 2017. Graduates from 2013-16 were not included in the analysis as they were more likely to be in training and probably not in their final practice destination.
The postcodes of the current locations of practice were transformed to Modified Monash Model categories for analyses. ${ }^{3}$ The model measures remoteness and population size on a scale of Modified Model (MM) 1 to MM 7, with MM 1 representing major cities and MM 7 representing very remote areas. Ethics approval was obtained from Flinders University Social and Behavioural Ethics Committee (7921).

\section{Results}

During this period, 1253 Flinders University medical students graduated, of whom 216 (17.2\%) participated in the PRCC RCS Program. Current practice location data of 42 graduates, including four PRCC graduates, could not be tracked using the 2017 AHPRA data, which resulted in 1121 students' graduate data available for analysis. The results indicated that higher proportions of PRCC graduates were working in a regional, rural or remote location in the year 2017 when compared with graduates of the city campus. More than one-third (36.8\%) of PRCC graduates were working in non-metropolitan MM 2-7, compared with $20.7 \%$ of city campus graduates (odds ratio [OR] 2.2; 95\% confidence interval [CI]: 1.6, 3.0; $P<0.001)$. The difference was even more evident when comparing smaller rural centres in MM 3-7 and MM 5-7 (Table 1). Data indicated $27.5 \%$ of PRCC graduates, compared with $10.9 \%$ of city campus graduates, were working in MM 3-5 (OR 3.1; 
95\% CI: 2.1, 4.4; $P<0.001)$. Significant impact was also apparent in the small and remote centres of MM 5-7, with PRCC graduates being 3.4 times more likely to be working in these centres when compared with city graduates (OR 3.4; 95\% CI: 2.1, 5.6; $P<0.0001)$. Among graduates with specialist qualifications (both general practice and non-general practice), PRCC graduates were more likely to report a speciality in general practice (58.8\%), compared with city-based graduates (35.4\%; OR 2.6; 95\% CI: $1.6,4.2 ; P<0.001)$. The retention of PRCC graduates in South Australia was also significantly greater, with $50.9 \%$ practising in the state in 2017 (OR 1.4; 95\% CI: 1.0, 1.9; $P<0.027)$.

\section{Discussion}

This study demonstrates the strong association between the Flinders University RCS Program in South Australia and long-term rural medical workforce outcomes, especially in rural general practice. The study results are consistent with emerging evidence regarding the contribution of rural community-engaged undergraduate medical training to addressing the medical workforce challenge in rural areas. ${ }^{4}$ As South Australia continues to face challenges in filling vacancies within rural general practice training streams, these results - which indicate that Flinders University RCS graduates continue to stay within South Australia - may contribute to general practice training developments to aid state-level retention. A limitation is that AHPRA data only captures graduates in full-time rural work; therefore, the graduates' contributions as locums or part time to rural workforce whose main practice is in the city are not included, potentially underestimating the contribution to the rural medical workforce. ${ }^{5}$ Nonetheless, the study represents positive career outcomes of one of Australia's long-running RCS programs.

\section{Authors}

Leesa Walker MBBS, FRACGP, GDCE, Academic Lead, Flinders University Rural Health SA, College of Medicine \& Public Health, Flinders University, SA

Table 1. Demographic and practice-based characteristics of graduates of the Flinders University medical program in South Australia, stratified by location of study

\begin{tabular}{|c|c|c|c|c|}
\hline \multicolumn{5}{|l|}{ Sex } \\
\hline Male & 496 (49.6\%) & 86 (40.6\%) & $1.5(1.1,2.0)$ & $5.7(0.019)$ \\
\hline
\end{tabular}

\section{Current specialist registration}

(both general practice and non-general practice)

\begin{tabular}{cccc}
\hline No & $473(47.3 \%)$ & $127(59.9 \%)$ & $0.6(0.4,0.8)$ \\
\hline Yes & $526(52.7 \%)$ & $85(40.1 \%)$ &
\end{tabular}

\section{Speciality in general practice}

\begin{tabular}{lccc}
\hline No & $340(64.6 \%)$ & $35(41.2 \%)$ & $2.6(1.6,4.2)$ \\
\hline Yes & $186(35.4 \%)$ & $50(58.8 \%)$ & $16.9(<0.001)$ \\
\hline
\end{tabular}

\section{Current location by state}

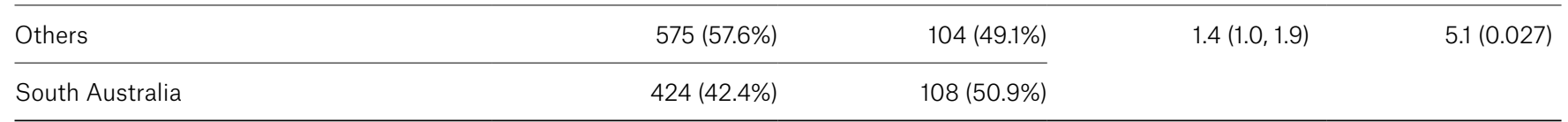

Current location by Modified Monash Model

\begin{tabular}{|c|c|c|c|c|}
\hline Non-metropolitan, MM 2-7 & 207 (20.7\%) & 78 (36.8\%) & $2.2(1.6,3.0)$ & $25.1(<0.001)$ \\
\hline
\end{tabular}

MM, Modified Monash 
Vivian Isaac PhD, Research Lead, Flinders University Rural Health SA, College of Medicine \& Public Health, Flinders University, SA

Lucie Walters PhD, Director, Adelaide Rural Clinical School, Adelaide University, SA

Jonathan Craig PhD, Vice President and Executive Dean, College of Medicine \& Public Health, Flinders University, SA

Competing interests: The authors report to have or previously had leadership responsibilities with the Flinders University Rural Clinical School Program.

Funding: The Flinders University Rural Clinical School Program is funded by the Australian Government Rural Health Multidisciplinary Training Program. Provenance and peer review: Not commissioned externally peer reviewed.

\section{Correspondence to:}

vivian.isaac@flinders.edu.au

\section{Acknowledgements}

The authors acknowledge the significant contribution of previous Directors of the Flinders University Rural Clinical School Professor Paul Worley and Professor Jennene Greenhill.

\section{References}

1. Walters LK, McGrail MR, Carson DB, et al. Where to next for rural general practice policy and research in Australia? Med J Aust 2017;207(2):56-58. doi: 10.5694/mja17.00216.

2. Worley P, Silagy C, Prideaux D, Newble D, Jones A. The parallel rural community curriculum: An integrated clinical curriculum based in rural general practice. Med Educ 2000;34(7):558-65. doi: 10.1046/j.1365-2923.2000.00668.x.

3. Department of Health. Modified Monash model. Canberra, ACT: DoH, 2020. Available at www. health.gov.au/health-workforce/health-workforceclassifications/modified-monash-model [Accessed 27 January 2021].
4. McGirr J, Seal A, Barnard A, et al. The Australian Rural Clinical School (RCS) program supports rural medical workforce: Evidence from a crosssectional study of 12 RCSs. Rural Remote Health 2019;19(1):4971. doi: 10.22605/RRH4971.

5. Playford D, Power P, Boothroyd A,

Manickavasagar U, Ng WQ, Riley G. Is the AHPRA national registration website effective in tracking Australian medical graduates' rural work? Aust J Rural Health 2013;21(5):249-53. doi: 10.1111/ ajr.12055. 